\title{
ESTUDOS BIOGEOQUÍMICOS NO COMPLEXO BÁSICO-ULTRABÁSICO DE PEDRAS PRETAS, SÃO SEPÉ, RS
}

\author{
MARIA DO CARMO LIMA E CUNHA*
}

\begin{abstract}
Biogeochemical studies in the area of the Basic-Ultrabasic Complex of Pedras Pretas, São Sepé, RS, reveal that the occurrence of a dwarf shrub vegetation is related to the presence of elements usually found in gabbroic and peridotitic lithologies which characterize this complex. The results of leaf-ash analyses of Scutia buxifolia indicate that this species is tolerant to high contents of Nickel, making it a biogeochemical indicator for this element in the studied area. The predominance of this plant is attesded by its adaptation capacity to soils depleted in essential nutrients, with low $\mathrm{Ca} / \mathrm{Mg}$ ratio. The plant, as well as the rock and soil geochemistry, proves the existence of a nickeliferous environment usually associated with serpentinized areas.
\end{abstract}

INTRODUÇÃo O Complexo de Pedras Pretas, município de São Sepé, RS, tem sido objeto de estudos que buscam a caracterização petrológica e geoquímica das rochas básicas e ultrabásicas que fazem parte do conjunto litológico que compõe o Escudo Sul-riograndense. Neste sentido, destacam-se os trabalhos de Villwock \& Loss (1970), Rêgo (1981) e Menegotto (1982).

Neste trabalho pretende-se caracterizar biogeoquimicamente a natureza básica e ultrabásica da área, por meio de análises químicas da vegetação que se desenvolve sobre os solos derivados de rochas peridotíticas e gabróicas que compõem o complexo. Tem-se como objetivo específico comprovar a existência de uma cobertura florística típica de solos serpentinizados, a exemplo do que acontece em várias províncias geológicas (Brooks 1972), que tende a concentrar elementos como níquel, ferro, magnésio, cromo e cobalto.

\section{CARACTERIZAÇÃO GEOLÓGICO-GEOBOTÂNICA DA} ÁREA DE ESTUDO Os dunitos e peridotitos (Rêgo 1981) que compõem o corpo ultrabásico abrangem a porção centro-norte da área e são circundados quase que totalmente pelo corpo básico, composto por rochas gabróicas que, por sua vez, são limitadas por falhamentos que as colocam em contato com o granito São Sepé (Sartori 1978, Fig. $1-\mathrm{A}$ e $1-\mathrm{B})$.

O contato entre as unidades de rochas máficas é de caráter transicional, conforme Menegotto (1982). Esta transição igualmente é retratada pela vegetação, conforme será visto adiante.

O relevo sobre as rochas ultrabásicas apresenta áreas de topo, estreitas e extensas, encostas íngremes e suaves, sopés e baixadas. Já a área que abrange o corpo básico é formada por pequenas encostas e baixadas.

Os solos, de um modo geral, são do tipo litólico, pouco desenvolvidos e com ausência de horizonte B. Nas baixadas, algumas vezes, percebe-se a existência de um solo mais espesso, do tipo hidromórfico.

Com relação à cobertura vegetal, observa-se uma nítida diferença na fisionomia da mesma de acordo com o contexto litológico geral da área.

Segundo Cole (1980), as rochas ultrabásicas distinguem- -se por um tipo de vegetação que, tanto na forma quanto na composição, contrasta com aquela de outros tipos de rochas, geralmente sendo de baixa estatura e de cobertura esparsa. Já as rochas básicas são recobertas por um solo residual relativamente espesso e usualmente caracterizado por uma vegetação mais luxuriante do que aquela sobre outros tipos de rochas, sendo o contato entre as duas unidades marcado pelo contraste da cobertura florística.

$\mathrm{Na}$ área de estudo, no granito circundante, a cobertura vegetal apresenta-se densa, sendo composta por árvores de médio porte e arbustos em profusão. À medida que se passa para o gabro, a vegetação torna-se rasteira, com predominância de gramíneas e tufos cespitosos, formando os chamados "campos sujos". Destaca-se aí a presença de Scutia buxifolia, vulgarmente conhecida como "coronilha". Esta geralmente ocorre como árvore de médio porte e, na área em apreciação, não ultrapassa dois metros. A presença arbustiva e sub-arbustiva desta espécie passa a ser uma característica constante no corpo ultrabásico, muito embora, em alguns locais, ocorra em associação com representantes das famílias Anacardiaceae, Lauraceae e Podocarpacea. A presença e predominância da espécie acima, principalmente sobre o peridotito e peridotito serpentinizado, é marcada por sua forma arbustiva, de poucos ramos espessamente cobertos por folhas pequenas de um verde claro intenso, não mostrando quaisquer feições teratológicas, com exceção de sua baixa estatura. De acordo com os dados existentes na literatura, um subtrato composto por rochas ultrabásicas invariavelmente é indicado pela presença de nanismo na vegetação.

MÉTODOS DE CAMPO E ANALI'TICO Na área de Pedras Pretas foram traçados dois perfis (Figs. 2 e 3 ) de amostragem, de direção N-S (A-B e C-D) sobre as litologias gabróica e peridotítica. Dada a predominância sobre as demais espécies, Scutia buxifolia foi o vegetal escolhido como objeto de amostragem em ambas as litologias consideradas. O espaçamento entre uma e outra estação, na maior parte das vezes, não ultrapassou 50 metros.

Os exemplares vegetais foram analisados por meio do método de calcinação a seco $\left(450^{\circ}\right)$, ataque com $\operatorname{HCL}(3 \mathrm{~N})$, seguido por determinação por espectrometria de absorção 


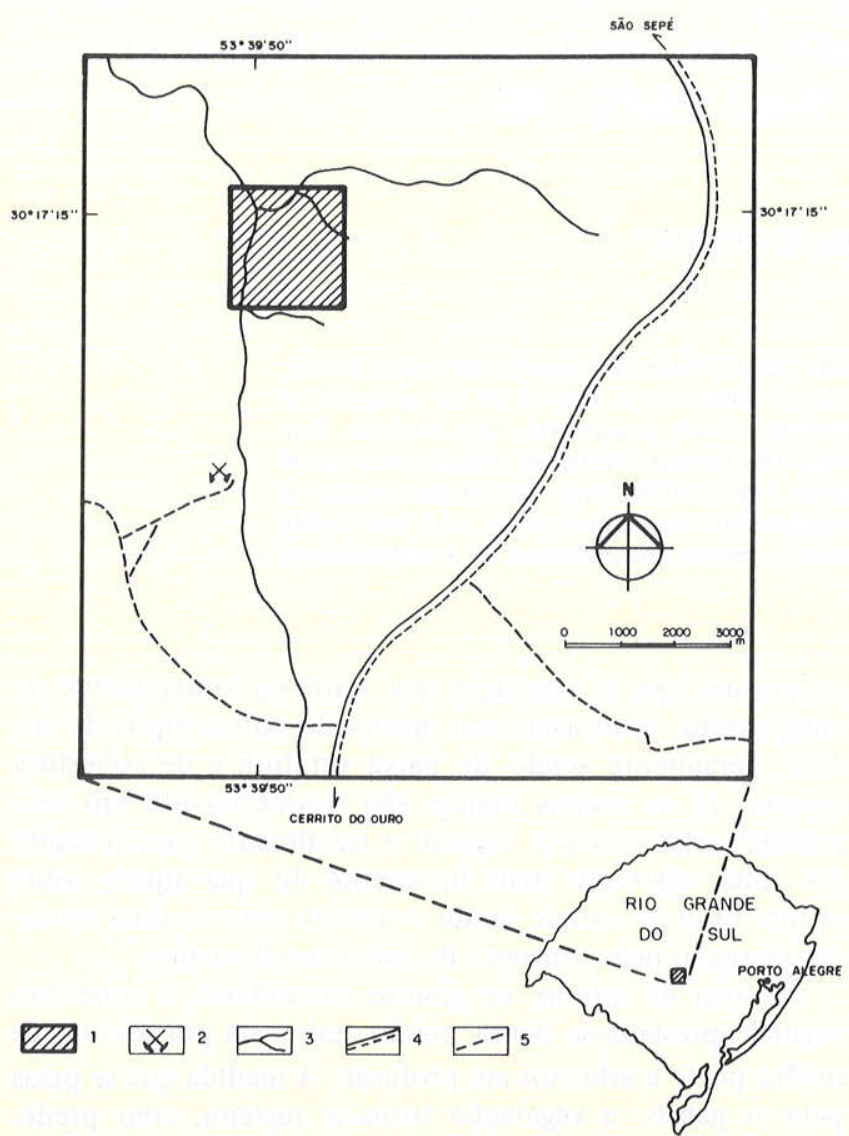

Figura 1-A - Mapa de localização geográfica da Área de Pedras Pretas, municipio de São Sepé, RS (Rêgo 1980, modificado) 1. Area da Fig. 1-B; 2. Pedreira desativada; 3. Rede de drenagem; 4. Estrada municipal; 5. Estrada secundária.

atômica para os elementos $\mathrm{Ni}, \mathrm{Cr}, \mathrm{Co}, \mathrm{Cu}, \mathrm{Pb}, \mathrm{Zn}, \mathrm{Ca}, \mathrm{Mg}$, $\mathrm{Fe}, \mathrm{Mn}, \mathrm{Na}$ e K.

INTERPRETAÇÃO BIOGEOQUIIMICA O estudo das relações entre a vegetação e o substrato geológico de Pedras Pretas foi feito no sentido de avaliar a distribuição da espécie escolhida, em função da geoquímica dos elementos encontrados nas litologias básicas e ultrabásicas e daqueles sem uma clara afinidade química com estas.

A interpretação dos resultados analíticos das cinzas das folhas de Scutia buxifolia revelou que o $\mathrm{Ni}$, o $\mathrm{Cu}$, o $\mathrm{Pb}$, o $\mathrm{Mg}$, o $\mathrm{Fe}$ e o $\mathrm{K}$ ocorrem em teores mais elevados na área do peridotito; nas rochas gabróicas, os elementos que se mostram em quantidade maior, na espécie, são o $\mathrm{Mn}$, o $\mathrm{Zn}$ e o $\mathrm{Ca}$. $\mathrm{O} \mathrm{Cr}$, o $\mathrm{Co}$ e o $\mathrm{Na}$ têm concentrações iguais em ambas as litologias, conforme pode-se observar na Tabela 1 .

$\mathrm{O}$ fato de o níquel e o magnésio terem suas médias mais altas e o cálcio sua média mais baixa nos vegetais que ocorrem no corpo ultrabásico condiz com os dados de Cole (1971, 1973, 1980) e Cannon (1971), relativos às concentrações destes elementos em plantas que se desenvolvem em solos derivados de rochas básicas e ultrabásicas.

O ferro é considerado por Menegotto (1982) como um elemento residual, concentrando-se nas fáceis de maior grau de alteração, sob a forma de oólitos; daí sua pouca disponibilidade para a planta. Contudo, pela Tabela 1 vê-se que este elemento, nas cinzas da espécie estudada, reflete, em

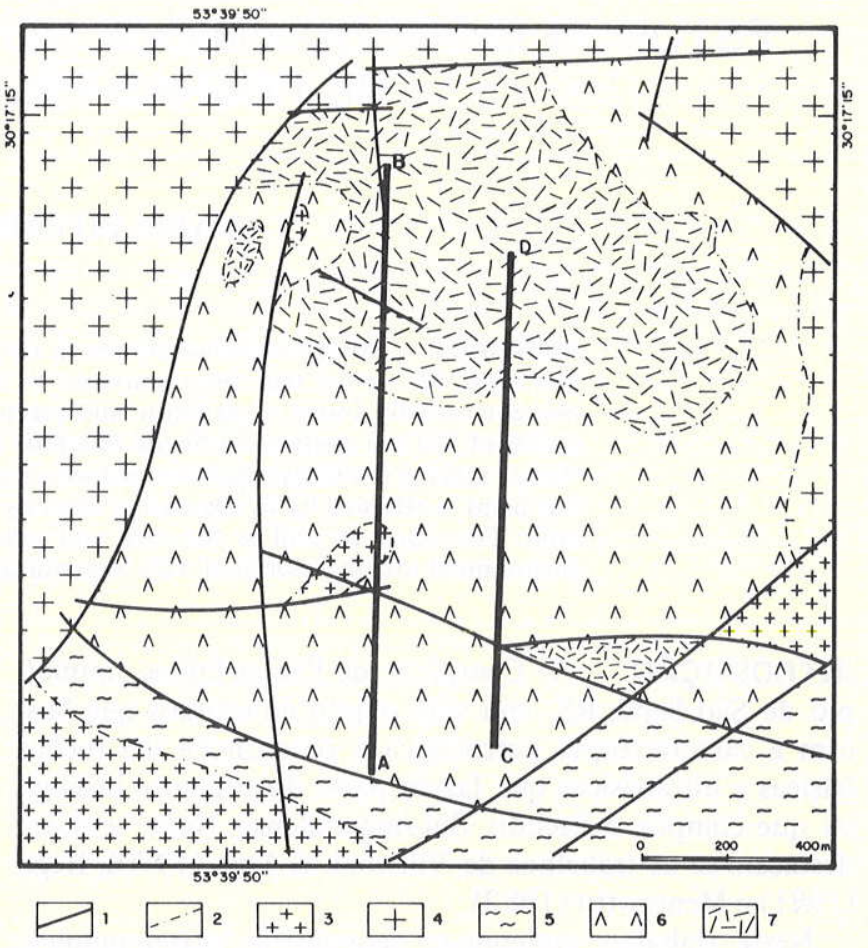

Figura 1-B - Mapa geológico da Area de Pedras Pretas, municipio de São Sepé, RS (Menegotto 1982, modificado)

1. Falhas; 2. Contato geológico; 3. Microgranito; 4. Granito; 5. Metamorfito; 6. Gabro; 7. Peridotito.

parte, a composição ferro-magnesiana do peridotito. Já o aumento do cobre e do chumbo parece estar vinculado à presença de sulfetos disseminados nas zonas fraturadas do corpo ultrabásico.

É digno de nota, entretanto, a presença de valores significativos de potássio nas cinzas dos vegetais que povoam o peridotito, uma vez que os solos derivados deste tipo de rocha são bastante deficientes em nutrientes essenciais, principalmente nitrogênio, fósforo e potássio. Este fato também chamou a atenção de Lee et al. (1977) quando, ao estudarem os solos serpentínicos da Nova Caledônia, observaram que as espécies existentes sobre tais solos acumulam quantidades relativamente altas de potássio, sendo o contrário o esperado.

Nas rochas gabróicas, o aumento de zinco e de manganês na espécie estudada em relação aos seus valores quando sobre o peridotito, embora pouco expressivo, possivelmente seja decorrente da maior disponibilidade destes elementos no corpo básico. Isto porque nas rochas gabróicas o desenvolvimento de um solo residual, relativamente mais espesso, é resultado de um processo de alteração que viabiliza uma maior solubilização tanto do zinco como do manganês. Além disso, o maior enriquecimento de zinco na planta, em relação ao cobre, por exemplo, deve-se ao fato de que o primeiro é mais fracamente sorvido nas partículas do solo do que o segundo (Krauskopf 1970), podendo ser transportado em solução por longas distâncias. 

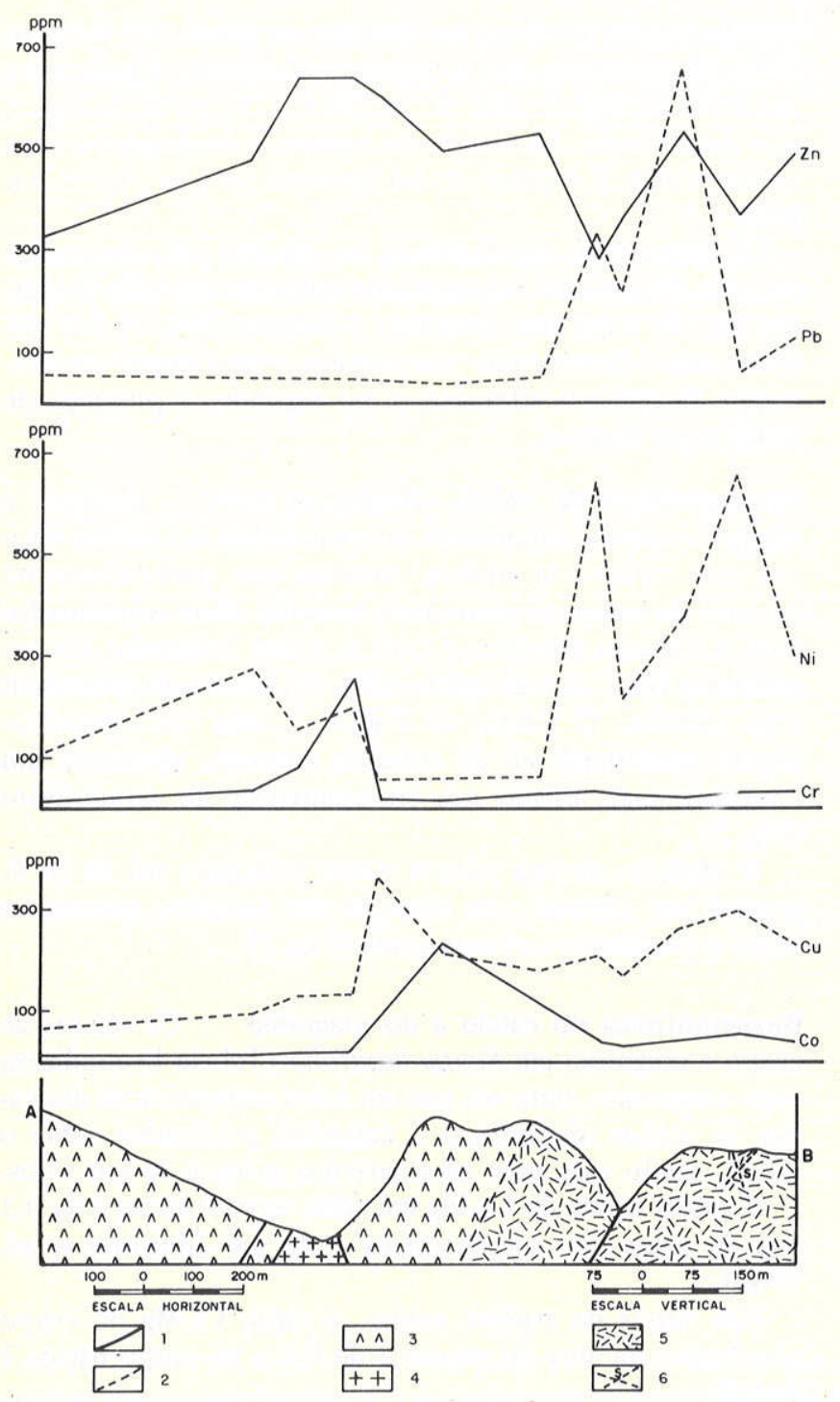

Figura 2 - Perfis biogeoquímicos: variação dos teores de $\mathrm{Zn}, \mathrm{Pb}, \mathrm{Ni}, \mathrm{Cr}$, Cu e Co em Scutia buxifolia (ppm em cinzas de folhas) em relação a topografia e litologias (A-B). 1. Falha; 2. Contato; 3. Gabro; 4. Granito; 5. Peridotito; 6. Serpentinito fraturado.

Com relação aos baixos valores de cromo e cobalto nas cinzas de Scutia buxifolia (em ambas as litologias), no caso do cromo deve-se à sua pouca disponibilidade à planta por ocorrer sob a forma de cromita; no caso do cobalto, por ocorrer como um elemento químico residual, cujos teores, mesmo nesta fase, são inferiores a 200 ppm na área estudada, conforme Menegotto (1982).

O sódio, na área de Pedras Pretas, mostra perdas progressivas da rocha para o solo, mas neste tende a concentrar-se por absorção aos argilo-minerais (Menegotto op. cit.). Isto, aliado à sua não essencialidade e absorção passiva por parte da planta, explica sua baixa concentração nas cinzas dos vegetais em ambos os tipos litológicos.

Biogeoquímica do níquel Geralmente, a absorção de um elemento menor ou traço, por uma dada espécie, está vinculada à quantidade deste elemento no meio e ao $\mathrm{pH}$ do solo, tendendo a aumentar quando os níveis de $\mathrm{pH}$ decrescem. Para Mishra \& Kar (1974), o níquel trocável do solo
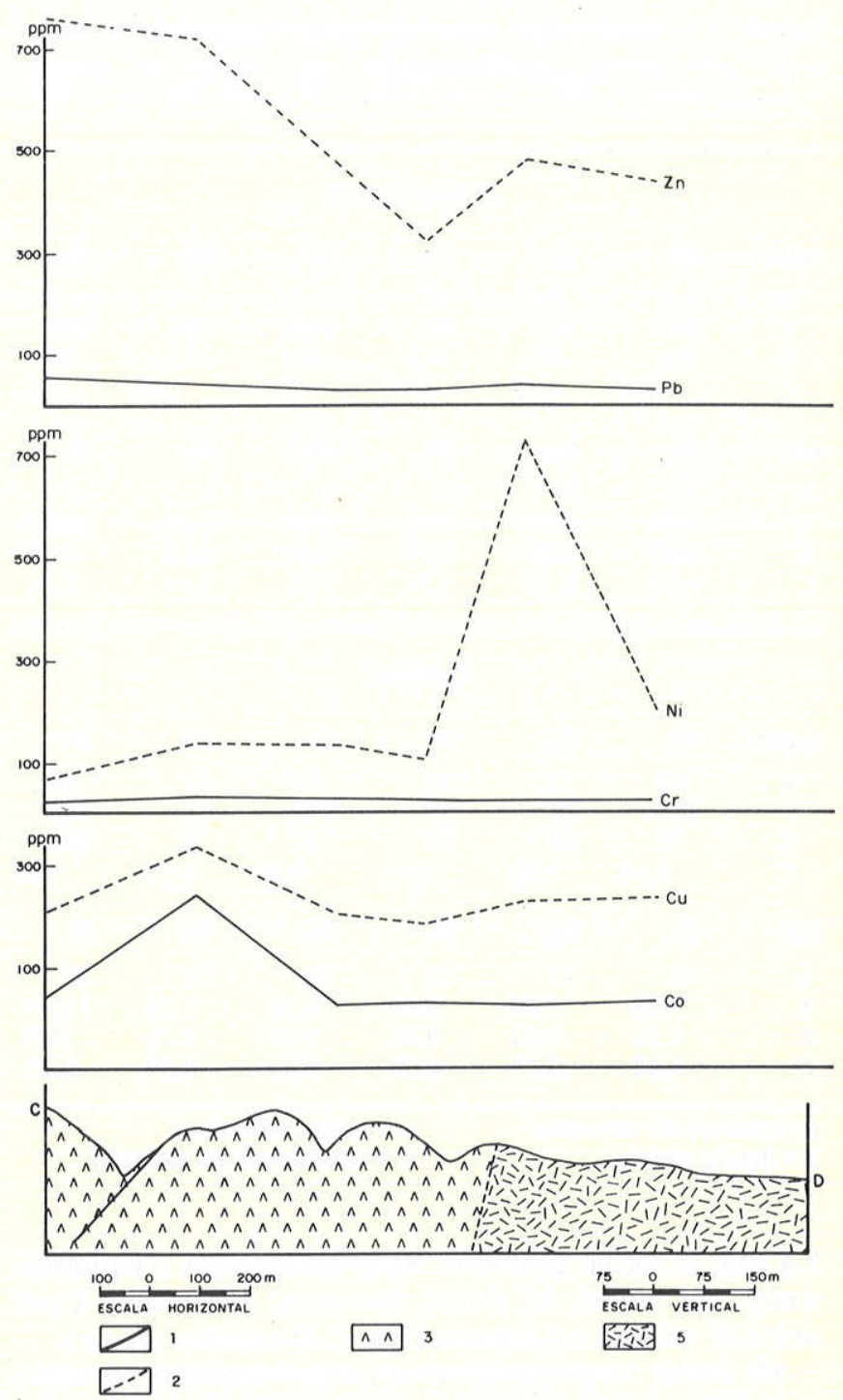

Figura 3 - Perfis biogeoquímicos: variação dos teores de $\mathrm{Zn}, \mathrm{Pb}, \mathrm{Ni}, \mathrm{Cr}, \mathrm{Cu}$ e Co em Scutia buxifolia (ppm em cinzas de folhas) em relação a topografia e litologias (C-D). 1. Falha; 2. Contato; 3. Gabro; 4. Granito; 5. Peridotito; 6. Serpentinito fraturado.

aumenta com o aumento de acidez do mesmo, sendo o $\mathrm{pH}$ um fator condicionante no processo de absorção. Uma vez que os valores de $\mathrm{pH}$ das águas subterrâneas de Pedras Pretas (Menegotto 1982) estão em torno de 6,5 a 7, os teores de níquel encontrados em Scutia buxifolia refletem que a sua disponibilidade está principalmente vinculada ao conteúdo total presente no solo, não sendo o $\mathrm{pH}$, neste caso, um fator limitante no mecanismo da absorção.

$\mathrm{O}$ cálculo das relações $\mathrm{Co} / \mathrm{Ni} / \mathrm{Cu}$ nas cinzas da espécie em questão mostra que para o gabro a média destas é de 1:8:5 e sobre o peridotito é de 1:14:7. De acordo com Malyuga (1964), a proporção $\mathrm{Co} / \mathrm{Ni} / \mathrm{Cu}$ em cinzas de plantas ocorrentes em áreas com depósitos de níquel tipo silicato é da ordem de 1:15:3, mostrando um enriquecimento do níquel em detrimento do cobre, já que a relação destes elementos em outros tipos de rochas é de 1:2,5:10.

Pelo perfil da Figura 2 percebe-se que os picos mais altos do níquel na espécie considerada ocorrem sobre a litologia peridotítica serpentinizada ou próximo ao contato por fa- 
Tabela 1 - Parâmetros estatísticos dos elementos considerados em Scutia buxifolia (ppm em cinzas de folhas). Complexo Básico-Ultrabásico de Pedras Pretas, São Sepé,RS.

\begin{tabular}{|c|c|c|c|c|c|c|}
\hline \multirow[b]{2}{*}{ (ppm) } & \multirow[b]{2}{*}{$\mathrm{Ni}$} & \multicolumn{3}{|c|}{ PERIDOTITO } & \multirow[b]{2}{*}{$\mathbf{P b}$} & \multirow[b]{2}{*}{$\mathrm{Zn}$} \\
\hline & & $\mathrm{Cr}$ & Co & $\mathrm{Cu}$ & & \\
\hline $\mathrm{n}$ & 7 & 7 & 7 & 7 & 7 & 7 \\
\hline $\mathrm{x}$ & 440 & 26 & 32 & 230 & 205 & 418 \\
\hline $\mathrm{S}$ & 225 & 4,5 & 9,3 & 40 & 225 & 88 \\
\hline $\mathrm{C}$ & 0,50 & 0,18 & 0,29 & 0,17 & 1,00 & 0,21 \\
\hline$(\%)$ & $\mathrm{Ca}$ & Mg & $\mathrm{Fe}$ & Mn & $\mathrm{Na}$ & $\mathbf{K}$ \\
\hline $\mathrm{n}$ & 7 & 7 & 7 & 7 & 7 & 7 \\
\hline $\mathrm{x}$ & 3,30 & 5,00 & 0,50 & 0,04 & 1,00 & 15,20 \\
\hline S & 0,69 & 0,54 & 0,17 & 0,01 & 0,64 & 2,50 \\
\hline $\mathrm{C}$ & 0,20 & 0,10 & 0,34 & 0,25 & 0,64 & 0,16 \\
\hline
\end{tabular}

\section{GABRO}

\begin{tabular}{|c|c|c|c|c|c|c|}
\hline (ppm) & $\mathrm{Ni}$ & $\mathrm{Cr}$ & Co & $\mathrm{Cu}$ & $\mathrm{Pb}$ & $\mathrm{Zn}$ \\
\hline $\mathrm{n}$ & 12 & 12 & 12 & 12 & 12 & 12 \\
\hline $\mathrm{x}$ & 115 & 29 & 38 & 190 & 41 & 555 \\
\hline $\mathrm{S}$ & 70 & 19 & 32 & 87 & 9 & 142 \\
\hline $\mathrm{C}$ & 0,60 & 1,00 & 0,85 & 0,45 & 0,23 & 0,25 \\
\hline$(\%)$ & $\mathrm{Ca}$ & Mg & $\mathrm{Fe}$ & Mn & $\mathrm{Na}$ & $\mathbf{K}$ \\
\hline $\mathrm{n}$ & 12 & 12 & 12 & 12 & 12 & 12 \\
\hline $\mathrm{x}$ & 7,80 & 3,60 & 0,40 & 0,10 & 1,10 & 11,10 \\
\hline $\mathrm{S}$ & 2,26 & 0,64 & 0,26 & 006 & 0,76 & 3,60 \\
\hline $\mathrm{C}$ & 0,28 & 0,17 & 0,60 & 0,43 & 0,69 & 0,32 \\
\hline
\end{tabular}

$\mathrm{n}=$ número de amostras

$\mathrm{S}=$ desvio padrão

$\mathrm{X}=$ média aritmética

$\mathrm{C}=$ coeficiente de variação

lha com as rochas gabróicas. Neste último caso, o enriquecimento em níquel, na planta, deve estar relacionado à presença de sulfetos em fraturas (Fig. 3; Menegotto op. cit).

Os dados biogeoquímicos do níquel sugerem, portanto, que a distribuição da espécie estudada é influenciada pelos teores deste elemento no solo e na rocha. comprovando um ambiente niquelífero e a efetividade do método na diferenciação entre as rochas básicas e as ultrabásicas.

Biogeoquímica do cromo e do cobalto Os valores relativamente baixos destes dois elementos em Scutia buxifolia, quando comparados com aqueles de solo (Menegotto op. cit.) e rochas (Rêgo 1981), principalmente no peridotito, devem ser devidos à sua baixa mobilidade, já que o cromo concentra-se como cromita e o cobalto é fortemente adsorvido por óxidos de manganês ou limonita, daí a sua pouca disponibilidade à planta, via solução do solo.

Um outro fator que condiciona a presença de baixos valores de cromo e cobalto na espécie é seu alto grau de toxicidade, fazendo com que o vegetal acione o seu mecanismo de exclusão, através do qual impede a absorção de teores excessivos destes elementos. A isto soman-se os valores pouco ácidos de $\mathrm{pH}$ do solo, que fazem com que haja um decrescimo de disponibilidade do cromo e do cobalto para a planta.

O perfil do cromo (Fig. 2) revela que os seus valores mais altos ocorrem associados à intrusão granítica que corta as rochas gabróicas, refletindo uma maior concentração deste elemento no solo, ocasionada provavelmente pela presença de minerais de minérios em fraturas no gabro. No restante do perfil percebe-se um aumento muito pouco significativo nas áreas serpentinizadas do peridotito. No perfil da Figura 3 , a distribuição do cromo na espécie é homogênea, com valores muito próximos do background para as plantas em geral.

Os picos mais significativos do cobalto são observados em uma das porções topograficamente mais elevadas do perfil (Fig. 2) e em área associada a fraturas (Fig. 3). No primeiro caso, devem estar relacionados a uma maior concentração de máficos alterados e, no segundo, à presença de sulfetos em fraturas.

Biogeoquímica do cobre, chumbo e zinco Embora o cobre e o zinco comumente se concentrem em rochas básicas, seus valores, na espécie, retratam que, particularmente no caso do zinco, os teores mais elevados estão relacionados com a intrusão granítica e com as zonas fraturadas do serpentinito (Fig. 2) e do gabro (Fig. 3), revelando associação com sulfetos. O cobre, na Figura 3, tem um comportamento semelhante ao do cobalto; contudo, apresenta um contraste mais nítido nos fraturamentos do serpentinito (Fig. 2).

O chumbo mostra valores muito próximos aos de background em plantas com exceção das amostras ocorrentes sobre o peridotito serpentinizado (Fig. 2).

Biogeoquímica do cálcio e do magnésio Os valores de cálcio e magnésio em Scutia buxifolia (Tabela 1) condizem com o esperado, uma vez que em solos serpentínicos derivados de rochas ultrabásicas o magnésio predomina sobre o cálcio, sendo esta uma característica própria de tais solos.

A razão típica de $\mathrm{Ca} / \mathrm{Mg}$ em solos serpentínicos é de 0,3 e a de solos não serpentínicos é de 3,0 (Barbour et al. 1980).

Nas cinzas da espécie acima, a razão $\mathrm{Ca} / \mathrm{Mg}$ no corpo ultrabásico da área de estudo é de 0,6 e no corpo básico é de 2,0 .

Os valores absolutos de magnésio em Scutia buxifolia, sobre o peridotito, são da ordem de $5 \%$ e os de cálcio de $3 \%$. Nas rochas gabróicas observa-se o inverso, sendo de $3 \%$ para o magnésio e $8 \%$ para o cálcio.

De acordo com os dados de Connor \& Shacklette (1975), os valores de magnésio encontrados em plantas que se desenvolvem sob condições normais são da ordem de 1,5 a $10 \%$, e os de cálcio de 12 a $26 \%$. Percebe-se, portanto, que o suprimento de cálcio em Scutia buxifolia, quando sobre os solos derivados das ultrabásicas, é bastante inferior ao comumente encontrado.

Dos demais elementos analisados em Scutia buxifolia (Fe, Mn, Na e K), somente o potássio encontra-se em teores acima da média para as plantas em geral, fato que surpreende, dado os baixos valores deste elemento em solos derivados de rochas serpentinizadas. Provavelmente sua alta concentração, na espécie acima, seja decorrente de sua grandè mobilidade e fácil redistribuição dentro da estrutura vegetal.

O sódio, por sua vez, conforme já explicado, além de ser um elemento considerado não essencial à planta, embora algumas vezes possa ter efeitos benéficos em alguns vegetais (Epstein 1975), é absorvido de maneira passiva, sendo que a sua concentração está na dependência de sua disponibilida- 
de no meio e ao mesmo tempo de sua necessidade por parte do vegetal.

\section{CAPACIDADE SELETIVA E CONCENTRADORA DE} SCUTIA BUXIFOLIA A diferença de concentração de determinados elementos, em determinadas espécies em um mesmo local, segundo Gerloff (1963), decorre de um mecanismo responsável por esta seletividade com possíveis efeitos benéficos de tais concentrações ao vegetal.

Segundo o autor acima, no que diz respeito às plantas que se desenvolvem sobre solos serpentínicos, os efeitos do ambiente nutricional na distribuição das espécies e as discussões relativas aos fatores responsáveis pelo crescimento limitado destas, em tais áreas, são bastante controvertidos, uma vez que estes solos são pouco férteis, com uma baixa razão $\mathrm{Ca} / \mathrm{Mg}$ e alto conteúdo de elementos conhecidos como tóxicos, mesmo, em alguns casos, a baixas concentrações.

Muitos autores acreditam que a capacidade de sobrevivência das plantas em ambientes desta natureza esteja ligada à sua tolerância aos baixos teores de cálcioe aos altos teores de magnésio; outros atribuem a tolerância das mesmas aos altos valores de níquel e/ou cromo.

Para Epstein (1975), plantas de uma dada espécie que ocorrem tanto sobre solos serpentínicos como não serpentínicos, ou têm suficiente plasticidade fenotípica para ajustarem-se a ambos os ambientes, ou os seus indivíduos se diferenciam em ecótipos edáficos. Deste modo, um ou outro fato poderia explicar a presença de Scutia buxifolia predominando sobre as demais espécies, tanto sobre as rochas gabróicas, como sobre as peridotíticas da área de Pedras Pretas, e cuja concentração de níquel, cálcio e magnésio (Tabela 1), na planta, varia de acordo com a diferenciação litológica e geoquímica da área.

Gerloff (op cit.) explica que as diferenças quantitativas das necessidades de certos elementos para as plantas estão vinculadas às variações na capacidade de absorção ou translocação destes elementos, e os diferentes mecanismos que atuam na absorção devem estar ligados aos agentes quelantes. Por sua vez, os quelatos que transformam os íons absorvidos em formas inativas também estão associados aos diferentes graus de exigência da planta e às variações na sua susceptibilidade aos efeitos prejudiciais dos elementos metálicos ou traços.

Seguindo esta linha de raciocínio, o mecanismo fisiológico de tolerância da espécie aqui estudada age de modo que mesmo os elementos potencialmente tóxicos são absorvidos e tornam-se inócuos em seu interior.

As evidências de que certas espécies apresentam tolerância múltipla a elementos com potencial nocivo (Gregory \& Bradshaw 1965) são comprovadas na Tabela 2, pelas correlações positivas entre o cobalto e manganês, no peridotito, níquel e cromo e cobre e cobalto, no gabro, onde observa-se a inexistência de antagonismo no processo de absorção destes elementos, e sugerindo que a Scutia buxifolia os absorve de maneira a satisfazer as suas necessidades em termos de micronutrição, em função do ambiente em que vive. Pela Tabela 2 observa-se ainda que:

- as correlações positivas entre o cobre e magnésio, cobre e ferro e ferro e magnésio, no gabro, devem estar associadas ao fato de que estes três elementos são essenciais no processo de fotossíntese, não competindo entre si em
Tabela 2 - Coeficientes de correlação ordinal entre os elementos analisados em Scutia buxifolia (ppm em cinzas de folhas)

AREA DO PERIDOTITO ${ }^{+}$

\begin{tabular}{|c|c|c|c|c|c|c|c|c|c|c|c|c|}
\hline & $\mathrm{Ni}$ & $\mathrm{Cr}$ & co & $\mathrm{Cu}$ & Po & $\mathrm{zn}$ & ca & Mg & $\mathrm{Fe}$ & $\mathrm{Mn}$ & $\mathrm{Na}$ & $\mathbf{K}$ \\
\hline $\mathrm{Ni}$ & $=$ & 0,54 & 0,40 & 0,15 & 0,04 & 0,02 & $-0,64$ & 0,73 & 0,54 & 0,18 & 0,43 & $-0,78$ \\
\hline $\mathrm{Cr}$ & 0,54 & 0.31 & 0,31 & $-0,32$ & 0,00 & $-0,79$ & $-0,21$ & 0,03 & 0,65 & 25 & 0,42 & $-0,08$ \\
\hline Co & $\begin{array}{l}0,40 \\
0,15\end{array}$ & $\begin{array}{r}0,31 \\
-0,32\end{array}$ & 0.61 & 0,61 & $\begin{array}{r}0,29 \\
-0,17\end{array}$ & & $\begin{array}{l}-0,33 \\
-0,14\end{array}$ & $\begin{array}{r}-0,07 \\
0,40\end{array}$ & $\begin{array}{l}0,72 \\
0,15\end{array}$ & $\begin{array}{l}0,83 \\
0.58\end{array}$ & 0,22 & $-0,25$ \\
\hline $\mathrm{Pb}$ & $\begin{array}{l}0,15 \\
0,04\end{array}$ & $\begin{array}{r}-0,32 \\
0,00\end{array}$ & $\begin{array}{l}0,61 \\
0.29\end{array}$ & $-0,17$ & $-0,17$ & $\begin{array}{l}0,40 \\
0,02\end{array}$ & $-0,47$ & $\begin{array}{r}0,40 \\
-0,11\end{array}$ & $\begin{array}{l}0,13 \\
0,07\end{array}$ & $\begin{array}{r}0,58 \\
-0,10\end{array}$ & $\begin{array}{l}-0,21 \\
-0,21\end{array}$ & $\begin{array}{l}-0,12 \\
-0,10\end{array}$ \\
\hline $\mathrm{Zn}$ & 0,02 & $\begin{array}{r}-0,79 \\
\end{array}$ & $-0,19$ & 0,40 & 0,02 & - & 0,14 & 0.51 & 0.54 & 0,79 & $-0,14$ & $\begin{array}{l}-0,10 \\
-0,03\end{array}$ \\
\hline $\mathrm{Ca}$ & 0,64 & $-0,21$ & $-0,33$ & $-0,14$ & 0,47 & $-0,14$ & & $-0,50$ & $-0,60$ & $-0,35$ & $-0,70$ & $-0,22$ \\
\hline $\begin{array}{c}\mathrm{Mg}_{\mathrm{g}} \\
\mathrm{F}_{\mathrm{g}}\end{array}$ & 0,73 & $-0,03$ & $-0,07$ & 0,40 & 0,11 & 0,51 & $\begin{array}{r}-0,50 \\
-060\end{array}$ & 009 & 0,09 & 0,17 & $-0,02$ & $\begin{array}{l}-0,81 \\
-0.07\end{array}$ \\
\hline $\begin{array}{l}\mathrm{Fe} \\
\mathrm{Mn}\end{array}$ & $\begin{array}{l}0,54 \\
0,18\end{array}$ & 0,65 & $\begin{array}{l}0,72 \\
0.83\end{array}$ & $\begin{array}{l}0,15 \\
0,58\end{array}$ & $-0,07$ & $\begin{array}{r}0,54 \\
-0,19\end{array}$ & $\begin{array}{l}-0,60 \\
-035\end{array}$ & 0,09 & 0.79 & 0,79 & 0,73 & $\begin{array}{l}-0,07 \\
0,04\end{array}$ \\
\hline & $\begin{array}{l}0,18 \\
0,43\end{array}$ & $\begin{array}{l}0,43 \\
0.42\end{array}$ & 0,22 & $\begin{aligned} 0,38 \\
-0,21\end{aligned}$ & $\begin{array}{l}-0,10 \\
-0,21\end{array}$ & $\begin{array}{l}-0,19 \\
-0,14\end{array}$ & $\begin{array}{l}-0,30 \\
-0,70\end{array}$ & $\begin{array}{r}0,02 \\
-0,17\end{array}$ & 0,75 & 0,33 & 0,33 & $\begin{array}{l}0,04 \\
0,22\end{array}$ \\
\hline K & $\begin{array}{r}-, 43 \\
-0,78\end{array}$ & $\begin{array}{r}0,08 \\
-0,08\end{array}$ & $\begin{array}{l}-0,25 \\
-0,25\end{array}$ & $-0,12$ & $-0,10$ & $-0,03$ & 0,22 & $-0,81$ & $\begin{array}{l}-0,07 \\
-1,07\end{array}$ & 0,04 & 0,22 & \\
\hline \multicolumn{13}{|c|}{ + número de amostras $=7 ;$ valor crítico $=0,71 ;$ nível de significáncia $=95$} \\
\hline \multicolumn{13}{|c|}{ AREA DO GABRO ${ }^{++}$} \\
\hline & $\mathrm{Ni}$ & $\mathrm{Cr}_{\mathrm{r}}$ & Co & $\mathrm{Cu}$ & Pb & $\mathrm{Zn}_{\mathbf{n}}$ & $\mathrm{Ca}_{\mathbf{a}}$ & $\mathrm{Mg}_{\mathrm{g}}$ & $\mathrm{Fe}$ & $\mathrm{Mn}$ & $\mathrm{Na}$ & $\mathrm{K}$ \\
\hline $\mathrm{Ni}$ & - & 0,73 & 0,55 & $-0,5$ & $-0,16$ & 0 & -0 & $-0,25$ & 0,05 & 9 & 0,59 & $-0,61$ \\
\hline & & & $-0,30$ & -0 & & & & -0 & & & & $-0,41$ \\
\hline Co & $-0,55$ & $-0,30$ & & 0,82 & 0,20 & $\begin{array}{l}0,37 \\
0.38\end{array}$ & $\begin{array}{l}-0,06 \\
-0,23\end{array}$ & 0,44 & 0,48 & $\begin{array}{l}0,24 \\
0.08\end{array}$ & $-0,07$ & $\begin{array}{l}0,50 \\
0,46\end{array}$ \\
\hline $\mathrm{Pb}$ & $\begin{array}{r}-0,50 \\
0.16\end{array}$ & $\begin{array}{l}-0,3 \\
-0,6\end{array}$ & $\begin{array}{l}0,82 \\
0.02\end{array}$ & -0.15 & $-0,15$ & $\begin{array}{l}0,38 \\
0.18\end{array}$ & $\begin{array}{r}-0,23 \\
0,45\end{array}$ & $\begin{array}{r}0,71 \\
-0,35\end{array}$ & $\begin{array}{r}0,64 \\
-0,46\end{array}$ & $\begin{array}{l}0,08 \\
0,17\end{array}$ & $\begin{array}{l}-0,06 \\
-0,14\end{array}$ & $\begin{array}{r}0,46 \\
-0,16\end{array}$ \\
\hline $\mathrm{Zn}$ & $\begin{array}{r}0,10 \\
-0,11\end{array}$ & $\begin{array}{r}-0,02 \\
0,23\end{array}$ & $\begin{array}{l}0,02 \\
0,37\end{array}$ & 0,38 & 0,18 & 0,18 & $\begin{array}{l}0,43 \\
0,01\end{array}$ & $\begin{array}{r}-0,35 \\
0,34\end{array}$ & $\begin{array}{r}-0,46 \\
0,07\end{array}$ & $\begin{array}{l}0,217 \\
0.21\end{array}$ & $\begin{array}{r}-0,14 \\
0,18\end{array}$ & $\begin{array}{r}-0,18 \\
0,18\end{array}$ \\
\hline $\mathrm{Ca}$ & $-0,59$ & $-0,41$ & $-0,06$ & $-0,23$ & & 0,01 & & $-0,25$ & $-0,48$ & 0,16 & $-0,50$ & 0,18 \\
\hline $\mathrm{Mg}$ & $-0,25$ & $-0,09$ & 0,44 & 0,71 & $-0,35$ & 0,34 & $-0,25$ & & 0,65 & $-0,64$ & $-0,26$ & 0,32 \\
\hline $\mathrm{Fe}$ & & 0,2 & 0 & 0,6 & $-0,46$ & 0,07 & $-0,4$ & 0,65 & & 0,09 & $\begin{array}{r}0,18 \\
0\end{array}$ & $-0,01$ \\
\hline Mn & $\begin{array}{l}0,22 \\
0.59\end{array}$ & 0 & 0,24 & $\begin{array}{r}0,08 \\
-0,0\end{array}$ & $\begin{array}{r}0,17 \\
\end{array}$ & 0,21 & $\begin{array}{r}0,16 \\
0.50\end{array}$ & $-0,64$ & 0,09 & & $-0,87$ & $\begin{array}{l}-0,48 \\
-0.48\end{array}$ \\
\hline $\begin{array}{l}\mathrm{Na} \\
\mathrm{K}\end{array}$ & $\begin{array}{r}0,61 \\
-0,59\end{array}$ & $\begin{array}{r}0,58 \\
-0,41\end{array}$ & $\begin{array}{l}-0,07 \\
.0,50\end{array}$ & $\begin{array}{r}-0,06 \\
0,46\end{array}$ & $\begin{array}{l}-0,14 \\
-0,16\end{array}$ & $\begin{array}{l}0,18 \\
0,18\end{array}$ & $\begin{array}{r}-0,00 \\
0,18\end{array}$ & $\begin{array}{r}-0,26 \\
0,32\end{array}$ & $\begin{array}{r}0,18 \\
-0,01\end{array}$ & $\begin{array}{l}-0,48 \\
-0,48\end{array}$ & $-0,48$ & $-0,48$ \\
\hline
\end{tabular}

suas funções metabólicas específicas;

- as relações entre ferro e cobalto, ferro e manganês e zinco e manganês, no peridotito, evidenciam a exigência, por parte da planta, da ação conjunta de íons metálicos divalentes para a ativação de muitas enzimas (Epstein 1975);

- o processo de absorção do sódio pela planta é feito de maneira passiva, o que possibilita a sua penetração no interior da estrutura vegetal. A associação com outros elementos, como o níquel e o cromo, na área do gabro, e com o ferro, no peridotito, revela a ausência de antagonismo mútuo na absorção destes com o sódio;

- a correlação positiva entre o níquel e o magnésio comprova que o níquel atua unido ao magnésio na síntese das porfirinas (componentes da clorofila), podendo, em alguns casos, até mesmo substituí-lo (Krauskopf 1967). Este fato indica que o níquel, para Scutia buxifolia, na área do peridotito, é um componente peculiar, já que desempenha um papel significativo, junto com o magnésio, no metabolismo vegetal;

- a ausência de linearidade entre o cromo e o zinco no peridotito, é entre o níquel e o cálcio no gabro, atesta a seletividade da espécie na absorção do zinco e do cálcio, essenciais e pouco tóxicos, em detrimento do níquel e do cromo;

- o aumento de absorção do níquel e do magnésio resulta na diminuição de absorção do potássio, mostrando que o níquel compete com o potássio tanto no gabro como no peridotito; já o magnésio compete com o potássio somente no peridotito, onde, embora este último tenha valores elevados na planta, sua absorção é reprimida em função dos altos teores de magnésio (Brooks 1972);

- a correlação negativa entre o níquel e o cobalto no gabro comprova a interferência do primeiro no processo de absorção do segundo, o que também foi constatado por Russel et al. 1968 (apud Mishra \& Kar 1974), revelando que a espécie é mais tolerante ao níquel que ao cobalto;

- o antagonismo observado entre o magnésio e o manganês no gabro, fato igualmente verificado por Williams \& Vlamis (apud Gerloff 1963), demonstra que o magnésio reprime a absorção do manganês. Para estes autores, o 
grau de antagonismo entre ambos varia de espécie para espécie, podendo inclusive não existir;

- embora a atividade do cromo na planta seja desconhecida, não havendo evidências de que este elemento seja essencial, geralmente em áreas de rochas básicas e ultrabásicas é um componente presente nas plantas, podendo até mesmo funcionar como um micronutriente, desde que em doses não muito elevadas. Sua relação negativa com o chumbo, no gabro, mostra que é menos tóxico que este último;

- o sódio, para Gerloff (op. cit.), tem efeito repressivo no processo de absorção do manganês, daí a relação negativa entre ambos, como se vê na Tabela 2 , na área do gabro.

Pelo estabelecimento das correlações tanto positivas como negativas entre os elementos estudados, na espécie considerada, fica claro que as diferenças fisiológicas existentes nas espécies vegetais devem ter inúmeras implicações nos efeitos mútuos ou antagônicos dos diversos íons que a planta absorve. A isto soman-se também os fatores exógenos que têm grande influência nos processos de absorção. Tais fatos levam à conclusão de que a susceptibilidade das plantas aos variados graus de toxicidade de alguns elementos permanencem no campo especulativo, sendo, portanto, motivo de muitos estudos ainda, conforme sugere Gerloff ( $o p$. cit.).

CONCLUSÕES Os estudos biogeoquímicos na área de Pedras Pretas revelam que a concentração dos elementos analisados nas cinzas de Scutia buxifolia, tanto sobre as rochas básicas como sobre as rochas ultrabásicas, não está diretamente relacionada aos parâmetros geo-ambientais, tais como $\mathrm{pH}$ e tipo de solo, relevo, natureza dos argilo-minerais etc., que geralmente condicionam o acúmulo de determinados elementos na vegetação. Na verdade, observa-se que a distribuição da espécie, na área considerada, depende mais de seu caráter tolerante e da disponibilidade dos elementos que se enriquecem nas rochas de natureza gabróica e peroditítica, conforme se vê nos itens que seguem:

- todos os exemplares vegetais amostrados contém quantidades de níquel bastante acima da média para as plantas em geral $(60 \mathrm{ppm})$, refletindo a alta concentração deste elemento na área estudada;

- sobre as áreas serpentinizadas, o teor de níquel, na espécie, aumenta do mesmo modo que este elemento se enriquece na rocha, o que atesta a efetividade da biogeo- química, tal como a geoquímica de solos e rochas, na diferenciação entre litologias básicas e ultrabásicas;

- o teor de níquel nas cinzas de Scutia buxifolia não indica necessariamente a presença de mineralização de níquel tipo silicatado mas, sem dúvida, confirma a presença do ambiente niquelífero que caracteriza composicionalmente as rochas ultrabásicas;

- nenhum dos exemplares amostrados revelou grandes quantidades de outros elementos metálicos, fato que tanto pode ser devido à habilidade da espécie em restringir a absorção daqueles elementos potencialmente tóxicos, como pela pouca disponibilidade dos mesmos no ambiente geoquímico;

- o acúmulo preferencial do níquel pela planta, em detrimento do cromo e do cobalto, pode ser determinado por aspectos fisiológicos e fitoquímicos próprios da espécie;

- a presença anômala de uma comunidade arbustiva sobre o complexo de Pedras Pretas deve ser estimulada pelos elevados valores de magnésio em detrimento do cálcio, que tendem a excluir muitas espécies e ao mesmo tempo possibilitam o desenvolvimento de uma mais tolerante;

- no sentido geobotânico, a fisionomia da vegetação, quando sobre as rochas gabróicas, é distinta daquela sobre as rochas de natureza peridotítica, sendo neste último caso diferenciada pela predominância de Scutia buxifolia com características naniformes.

- a concentração de níquel, cálcio e magnésio nas cinzas da espécie estudada varia de acordo com a diferenciação litológica-geoquímica da área.

Resumindo, concluiu-se que a distribuição de Scutia buxifolia no complexo básico-ultrabásico de Pedras Pretas deve estar relacionada ao seu alto poder de adaptação aos solos pobres em nutrientes básicos, com baixa razão cálcio/ magnésio e com teores significativos de níquel, cuja concentração na planta lhe confere um caráter indicador deste elemento.

Agradecimentos Expressamos nossos agradecimentos aos professores E. F. de Lima, L. V. S. Nardi e M. L. L. Formoso pelas críticas e sugestões; à Joyce Espíndola e Gisela R. de Castro pelas determinações analíticas; à Finep pelo auxílio financeiro; ao Laboratório de Geoquímica do Depto. de Geologia e ao CNPq pela concessão de bolsa de pesquisa que dá oportunidade ao desenvolvimento e continuidade de nossos trabalhos.

\section{REFERÊNCIAS BIBLIOGRÁFICAS}

BARBOUR, M.G.; J.H.; PITTS, W.D. - 1980 - Terrestrial Plant ecology. Califórnia, Benjamin/Cummings, $604 \mathrm{p}$.

BROOKS, R.R. - 1972 - Geobotany and biogeochemistry in mineral exploration. New York, Harper \& Row, 290 p.

CANNON, H.L. - 1971 - The use of plants in ground water surveys, geologic mapping and mineral prospecting. Taxon, 20:(2/3): 227-256.

COLE, M.M. - 1971 - The importance of environment in biogeographical/geobotanical and biogeochemical investigations. Geochemical Exploration, CIM, Spec. 11:414-425.

COLE, M.M. - 1973 - Geobotanical and biogeochemical investigations in the sclerophyllous woodland and shrub associations of the eastern goldfields area of Western Australia, with particular reference to the role of Hybanthus Floribunds
(Lindl.) F. Muell, as a Nickel indicator and accumulator plant. Jour. Appl. Ecol. 10: 269-320.

COLE, M.M. - 1980 - Geobotanical expression of orebodies. Institute of Mining and Metallurgy-Transactions, 89: Section B: 73-91.

CONNOR, J.J. \& SHACKLETTE, H.T. - 1975 - Background geochemistry of some rocks, soils, plants and vegetables in the conterminous United States. Washington, U.S. Geol. Surv. Prof. Paper, v. 574-F, 168 p.

EPSTEIN, E. - 1975 - Nutrição mineral das plantas. Princịpios $e$ perspectivas. São Paulo, Edusp, $341 \mathrm{p}$.

GERLOFF, G.C. - 1963 - Comparative mineral nutrition of plants. Annual Review of Plant Physiology, 14: 107-124.

GREGORY, R.P.G. \& BRADSHAW, A.D. - 1965 - Heavy metal 
tolerance in populations of Agrostis Tenuis Sibth. and other grasses. New Phytologist, 64:131-143.

KRAUSKOPF, K.B. - 1967 - Introduction to geochemistry. New York, McGraw-Hill, $721 \mathrm{p}$.

KRAUSKOPF, K.B. - 1970 - Geochemical of micronutrientes In: MORTVEDT, J.J.; GIORDANO, P.M.; LINDSAY, W.L. Micronutrients in agriculture. s.l. Soil Science Society of America, $630 \mathrm{p}$.

LEE, J.; BROOKS, R.R.; REEVES, R.D.; BOSWELL, C.R. - 1977 Plant Soil relationships in a New Caledonian serpentine flora. Plant and Soil, 46: 675-680.

MALYUGA, D.P. - 1964 - Biogeochemical methods of prospecting. New York, Consultants Bureau, 205 p.

MENEGOTTO,E. - 1982 - Alteração intempérica de rochas ultrabásicas em clima tropical - Evolução mineralógica e geoquímica em alguns maciços ultrabásicos do Rio Grande do Sul, Brasil. Porto Alegre, UFRGS, Tese de doutoramento, $356 \mathrm{p}$.
MISHRA, D. \& KAR, M. - 1974 - Nickel in plant growth and metabolism. The Botanical Review, 40: (4): 395-451.

RÊGO, I.T.S. - 1981 - Aspectos petrológicos e geoquímicos do Complexo Básico-Ultra-básico de Pedras Pretas, Rio Grande do Sul. Act. Geol. Leop. São Leopoldo, 5 :(10): 197-278.

SARTORI, P.L. - 1978 - Petrologia do Complexo Granítico de São Sepé - RS. Modelo evolucional de granitos do sul do Brasil. São Paulo, USP Instituto de Geociências, Tese de Doutoramento, $196 \mathrm{p}$.

VILLWOCK, J.A. \& LOSS, E.L. - 1970 - Um novo tipo de compelxo básico-ultrabásico na faixa serpentítica do Pré-Cambriano do Rio Grande do Sul. Notas e Estudos da Escola de Geologia, Porto Alegre, UFRGS, 2(1): 15-22.

MANUSCRITO

Recebido em 17 de janeiro de 1985 Revisão aceita em 20 de agosto de 1985

Qualquer homem que tenha conhecido a fome, o medo, ou o trabalho forçado, começa a entender que a proteção da natureza $o$ afeta diretamente.

Romain Gary, Les Racines du ciel 